NASA

Technical Memorandum 106623

AIAA-94-2937
Army Research Laboratory Technical Report ARL-TR-475

\title{
Vibration Signature Analysis of a Faulted Gear Transmission System
}

F.K. Choy and S. Huang

University of Akron

Akron, Ohio

J.J. Zakrajsek

Lewis Research Center

Cleveland, Ohio

R.F. Handschuh

Vehicle Propulsion Directorate

U.S. Army Research Laboratory

Lewis Research Center

Cleveland, Ohio

D.P. Townsend

Lewis Research Center

Cleveland, Ohio

Prepared for the

30th Joint Propulsion Conference

cosponsored by the AIAA, ASME, SAE, and ASEE

Indianapolis, Indiana, June 27-29, 1994

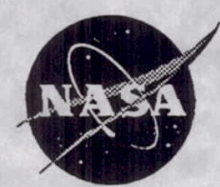

National Aeronautics and

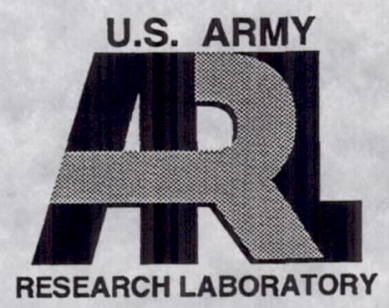




\title{
VIBRATION SIGNATURE ANALYSIS OF \\ A FAULTED GEAR TRANSMISSION SYSTEM
}

\author{
F. K. Choy and S. Huang \\ Department of Mechanical Engineering \\ University of Akron \\ Akron, Ohio 44325 \\ J.J. Zakrajsek \\ National Aeronautics and Space Administration \\ Lewis Research Center \\ Cleveland, Ohio 44135 \\ R. F. Handschuh \\ Propulsion Directorate \\ U.S. Army Aviation Systems Command \\ Lewis Research Center \\ Cleveland, Ohio 44135 \\ and \\ D.P. Townsend \\ National Aeronautics and Space Administration \\ Lewis Research Center \\ Cleveland, Ohio 44135
}

\begin{abstract}
$\underline{\text { Abstract }}$
A comprehensive procedure in predicting faults in gear transmission systems under normal operating conditions is presented. Experimental data was obtained from a spiral bevel gear fatigue test rig at NASA Lewis Research Center. Time synchronous averaged vibration data was recorded throughout the test as the fault progressed from a small single pit to severe pitting over several teeth, and finally tooth fracture. A numerical procedure based on the WignerVille distribution was used to examine the time averaged vibration data. Results from the Wigner-Ville procedure are compared to results from a variety of signal analysis techniques which include time domain analysis methods and frequency analysis methods. Using photographs of the gear tooth at various stages of damage, the limitations and accuracy of the various techniques are compared and discussed. Conclusions are drawn from the comparison of the different approaches as well as the applicability of the Wigner-Ville method in predicting gear faults.

\section{Introduction}

In the last two decades, with the ever increasing demand for higher power and performance, premature failures in high performance machinery often result in major production and financial losses, and sometimes even lead to catastrophic consequences. In the aerospace industry, one of the major concerns is the rotorcraft transmission system. Currently, on-board operational condition monitoring
\end{abstract}

systems for rotorcraft transmissions often fail to provide sufficient time between warning and failure so that safety procedures can be implemented. In addition, inaccurate interpretation of operating conditions often result in false alarms and unnecessary repairs and downtime. The development of an accurate machine health monitoring system for rotorcraft transmission systems will increase safety and reduce financial investments.

Three major types of vibration analysis have been used in the early detection of machine failure, namely, frequency analysis, various techniques using the time domain analysis, and joint time-frequency analysis.

For frequency analysis, the amplitude spectrum of the measured vibration signal is calculated and displayed in a continuous manner. ${ }^{15,18}$ This method is particularly powerful in identifying vibrations due to various mechanical elements in the system at their operating frequencies. For example, a gearbox will experience vibration at the fundamental and multiple harmonic frequencies of the gear tooth meshing frequency, which are usually different for each pair of gears in the gearbox. The changes in the frequency spectrum, such as an increase in the vibration amplitude at a particular frequency, or the appearance of modulation sidebands about that frequency, can often be identified and related to a single element in the complex system. Furthermore, abnormal vibration signals, caused by wear, deformation of the machine element, "ghost component" etc., which are sometimes difficult to quantify in the time domain, can 
be readily identified in the frequency spectrum. However, the spectral analysis technique is difficult to apply in a highly complex system, such as a helicopter gearbox, which may have as many as 30 gears and 50 bearings. The large number of spectral lines which these elements produce during normal operation can make it difficult to even detect changes in the spectrum, let alone to identify the sources by which these changes are generated. In addition, the modulation of the vibration signal of early fatigue cracks in the mechanical elements often yield sidebands which extended over a broad frequency range with low amplitude. Under these circumstances, the background noise level in the spectrum can easily mask the presence of the sidebands, and mechanical defects in the system may go undetected.

Time domain analysis is also used for the early detection of machine faults. ${ }^{9-11,17,19-21}$ The digitized time domain vibration signal is averaged over a large number of cycles, synchronous with the running speed of a particular machine element. This time synchronous averaging removes the background noise, leaving a more accurate estimate of the vibration signal of the component of interest. This process can be repeated for each machine element in the system to provide the vibration signal relative to that particular element. A variety of statistical based techniques are then applied to the averaged signal to extract specific fault information. In most machinery, vibration signals are often characterized by a variation of both amplitude and frequency with respect to time. For most mechanical faults, both the amplitude and frequency contents of the signal will shift during the period in which the damage is generated. The nature of these short-term variations in the time signal could prevent an accurate indication of the characteristics of the mechanical fault present.

The joint time-frequency analysis approach applies the Wigner-Ville Distribution (WVD) ${ }^{1-3,14,16}$ on the time vibration signal of the system. Unlike the Fourier Transform process, the WVD provides a instantaneous frequency spectrum of the system. The spectral density of the fundamental exciting frequency and its sidebands changes as the shaft rotates through a complete revolution. If the vibration repeats itself each revolution, a Fourier Transform will show a constant frequency spectrum, while the changing spectral density with time from the WVD provides information concerning the frequency distribution concentrated at that instant around the instantaneous frequency. Some success has been achieved in applying the WVD in gear transmission systems ${ }^{5,6,8,12,16}$ to recognize faults at various locations of the gear.

The objective of this paper is to examine and compare the three different approaches to detect gear wear and failure. The frequency domain analysis is based on the spectral display from a Fast Fourier Transform algorithm.
The time domain analysis includes the time synchronous averaged signal, and the statistical based techniques FM0, FM4, NA4*, and NB4* applied to the time averaged signal. The joint time-frequency analysis uses the WVD on the vibration data with special windowing techniques. All of the analysis methods are applied to the vibration data of a failure from the spiral bevel gear fatigue test rig in the NASA Lewis Research Center. Results from the various methods are compared and general conclusions are drawn from the results.

\section{Technical Approach}

As discussed in the previous section, three major methodologies: A) the frequency domain approach, B) the time domain approach, and C) the joint time-frequency approach are used in this study. The following is a description of the three methodologies:

\section{(A) Frequency Domain Techniques}

The frequency spectrum is found by applying a discrete FFT on the time averaged signal $x(t)$, such that the spectral components are

$$
\left.X(k)=T \sum_{i=0}^{N-1} x(t) \exp \mid \frac{-j 2 \pi i k}{N}\right)
$$

where

$$
\begin{array}{ll}
\mathrm{x}(\mathrm{t}) & =\text { time domain signal } \\
\mathrm{X}(\mathrm{k}) & =\text { frequency domain signal } \\
\mathrm{T} & =\text { sampling time interval } \\
\mathrm{N} & =\text { number of data points }
\end{array}
$$

The frequency components are examined in the frequency domain and compared with those obtained at various stages of the fault development in the spiral bevel pinion.

\section{(B) Time Domain Techniques}

Four different time domain techniques for early detection of gear tooth damage are used in this study for evaluation and comparison. All of the time domain techniques are applied to the vibration signal after it has been time synchronously averaged. These techniques are: FM0, FM4, NA4*, and NB4*. These parameters are defined as follows:

FM0 $0^{17}$ is a course fault detection parameter that compares the maximum peak to peak amplitude to the sum of the mesh frequencies and its harmonics

$$
F M 0=\frac{P P}{\sum_{i=1}^{n} A\left(f_{i}\right)}
$$


where

$\mathrm{PP} \quad=$ maximum peak to peak amplitude in signal

$\mathrm{A}\left(\mathrm{f}_{\mathrm{i}}\right)=$ amplitude at mesh frequency and harmonics

$\mathrm{n} \quad=$ total number of harmonics in frequency range

FM4 $4^{17}$ is an isolated fault detection parameter, and is given by the normalized kurtosis, of the resulting difference signal as

$$
F M 4=\frac{N \sum_{i=1}^{N}\left(d_{i}-\bar{d}\right)^{4}}{\left[\sum_{i=1}^{N}\left(d_{i}-\bar{d}\right)^{2}\right]^{2}}
$$

where

$$
\begin{array}{ll}
\mathrm{d}(\mathrm{t}) & =\mathrm{A}(\mathrm{t})-\mathrm{R}(\mathrm{t}) \\
\overline{\mathrm{d}} & =\text { mean value of } \mathrm{d}(\mathrm{t}) \\
\mathrm{A}(\mathrm{t}) & =\text { original time synchronous signal } \\
\mathrm{R}(\mathrm{t}) & =\text { regular meshing components plus their first } \\
& \text { order side bands } \\
\mathrm{N} & =\text { total number of data points in the time signal }
\end{array}
$$

NA4 ${ }^{* 4,20,21}$ is a general fault detection parameter with trending capabilities. A residual signal is constructed by removing regular meshing components from the time averaged signal. For NA4, the first order sidebands stay in the residual signal and the fourth statistical moment of the residual signal is then divided by the averaged variance of the residual signal, raised to the second power. The average variance is the mean value of the variance of all previous records in the run ensemble. This allows NA4 to compare the current gear vibration with the baseline of the system under nominal conditions. NA4 is given by the quasinormalized kurtosis equation shown below:

$$
N A 4 *(M)=\frac{N \sum_{i=1}^{N}\left(r_{i}-\bar{r}\right)^{4}}{\left\{\frac{1}{M} \sum_{j=1}^{N}\left[\sum_{i=1}^{N}\left(r_{i j}-\bar{r}_{j}\right)^{2}\right]\right\}^{2}}
$$

where

$$
\begin{array}{ll}
\mathrm{r} & =\text { residual signal } \\
\overline{\mathrm{r}} & =\text { mean value of residual signal } \\
\mathrm{N} & =\text { total number of data points in one time record } \\
\mathrm{i} & =\text { data point number in time record } \\
\mathrm{j} & =\text { time record number } \\
\mathrm{M} & =\text { current time record number in run ensemble }
\end{array}
$$

An enhancement to this parameter is given by NA4*, in which the value of the averaged variance is "locked" when the instantaneous variance exceeds a pre-determined value. ${ }^{4}$
This provides NA4 with enhanced trending capabilities, in which the kurtosis of the current signal is compared to the variance of the locked baseline signal under nominal conditions.

NB4 is another parameter similar to NA4 that also uses the quasi-normalized kurtosis given in equation (4). The major difference is that instead of using a residual signal, NB4 uses the envelope of the signal banpassed about the mesh frequency. Again, as with NA4*, NB4* is an enhancement to the NB4 parameter, in which the value of the average variance is "locked" when the instantaneous variance exceeds a pre-determined value. The equation for NB4* is given below:

$$
N B 4^{*}(M)=\frac{N \sum_{i=1}^{N}\left(s_{i}-\bar{s}\right)^{4}}{\left\{\frac{1}{M} \sum_{j=1}^{N}\left[\sum_{i=1}^{N}\left(s_{i j}-\bar{s}_{j}\right)^{2}\right]\right\}^{2}}
$$

and

$$
\mathrm{s}(\mathrm{t})=\text { magnitude of }\{\mathrm{b}(\mathrm{t})+\mathrm{i}\{\mathrm{H}[\mathrm{b}(\mathrm{t})]\}\}
$$

where

$\mathrm{b}(\mathrm{t}) \quad$ = time averaged signal bandpassed filtered about the meshing frequency

$\mathrm{H}[\mathrm{b}(\mathrm{t})]=$ the Hilbert Transform of $\mathrm{b}(\mathrm{t})$

$\mathrm{N} \quad=$ total number of data points in one time record

$\mathrm{i}$ = data point number in time record

$\mathrm{j} \quad=$ time record number

M = current time record number in run ensemble

\section{(C) Joint Time-Frequency Technique}

To examine the vibration signal in a joint timefrequency domain, the Wigner-Ville method ${ }^{1-3,14}$ is used in this study. While the FFT technique (eq. 1) can provide the spectral contents of the time signal, it cannot distinguish time phase change during a complete cycle of operation. In other words, it assumes that the time signals are repeatable for each time data acquisition window without considering the effects of any magnitude and phase changes during the sampling period. The Wigner-Ville distribution will provide an interactive relationship between time and frequency during the period of the time data window. The WVD (Wigner-Ville Distribution) can be written as:

$$
W(t, f)=\sum_{-\infty}^{\infty} x\left(t+\frac{\tau}{2}\right) x *\left(t-\frac{\tau}{2}\right) e^{-j 2 \pi f \tau} d \tau
$$

or in a discrete form as

$W_{x}(n T, f)=2 T \sum_{i=-L}^{L} x(n T+i T) x *(n T-i T) \cdot e^{-j 4 \pi f i \tau}$ 
where

$\mathrm{W}(\mathrm{t}, \mathrm{f})=$ the Wigner-Ville distribution in both the time domain $\mathrm{t}$ and frequency domain $\mathrm{f}$.

$\mathrm{x}(\mathrm{t}) \quad=$ the time signal

$\mathrm{T}=$ the sampling interval

$\mathrm{L} \quad=$ the length of time data used in the transform

To allow sampling at the Nyquist rate and eliminate the concentration of energy around the frequency origin due to the cross product between negative and positive frequency, ${ }^{1,3}$ the analytic signal was used in evaluating the WVD. The analytic signal $s(t)$ is defined as

$$
s(t)=x(t)+j H[x(t)]
$$

where

$$
\begin{aligned}
& H[x(t)]=\text { the Hilbert transform of } x(t) \text { defined by: } \\
& H[x(t)]=\frac{1}{\pi} \int_{-\infty}^{\infty} \frac{x(\xi)}{t-\xi} d \xi
\end{aligned}
$$

However, an alternative approach can be used to calculate the analytic signal using the frequency domain definition. The analytic signal $s(t)$ can be evaluated by calculating the FFT of the time signal $x(t)$, then setting the negative frequency spectrum to zero. The analytic signal can be obtained by evaluating the inverse FFT of the spectrum. To simplify the computational effort, the WVD can be evaluated using a standard FFT algorithm. Adopting the convention that the sampling period is normalized to unity, equation (8) can be rewritten as

$$
W_{x}(n, f)=2 \sum_{i=-L}^{L} x(n+i) x^{*}(n-i) \cdot e^{-j 4 \pi f i}
$$

As for the continuous time case, it is necessary only to evaluate the WVD at time zero.

Hence

$$
W_{x}(0, f)=2 \sum_{i=-L}^{L} k(i) e^{-j 4 \pi f i}
$$

where

$$
k(i)=s(i) s^{*}(-i)
$$

Equation 12 can be evaluated using the discrete FFT algorithm.

In order to avoid a repetition in the time domain WVD, a weighting function ${ }^{12}$ is added to the time data before the evaluation process. Such a process may decrease the resolution of the distribution, but it will eliminate the repetition of peaks in the time domain and the interpretation of the result will be substantially easier.

\section{Description of Experimental Procedure}

The fatigue damage on the test pinion shown in Figures 1 to 8 was obtained using the spiral bevel gear fatigue test rig illustrated in figure 9, at the NASA Lewis Research Center. The primary purpose of this rig is to study the effects of gear tooth design, gear materials, and lubrication types on the fatigue strength of aircraft quality gears. ${ }^{7}$ Because spiral bevel gears are used extensively in helicopter transmissions to transfer power between nonparallel intersecting shafts, the use of this fatigue rig for diagnostic studies is extremely practical. Vibration data from an accelerometer mounted on the pinion shaft bearing housing was captured using a personal computer with an analog to digital conversion board and anti-aliasing filter. The 12-tooth test pinion, and the 36-tooth gear have:, 0.5141 in pitch, 35 degree spiral angle, 1 in. face width, 90 degree shaft angle, and 22.5 degree pressure angle. The pinion transmits $720 \mathrm{hp}$ at nominal speed of $14,400 \mathrm{rpm}$. The test rig was started and stopped several times for gear damage inspection. The test was ended at 17.79 operational hours when a broken portion of a tooth was found visually during one of the shutdowns.

\section{Discussions of Results}

A series of pictures showing the deterioration of the pinion teeth at various stages of the test are illustrated in figures 1 to 8 . In figure 1 the initiation of a small pit on one of the pinion teeth during the first shutdown, at about five and a half hour into the test is shown. As the test progressed, the rig was shut down seven more times to examine the severity of the pitting and its relationship with the corresponding vibrations. Figures 2 to 4 show the increase of the damaged area at the pinion tooth as the elapsed time increased to $6.55,8.55$, and $10.03 \mathrm{hr}$ respectively. Note that in figure 5 , as the elapsed time increased to $12 \mathrm{hr}$, the damage of the pinion tooth increased to 75 percent of the tooth surface. At this stage, pitting also initiated on the adjacent tooth and continued to grow as the time increased to $14.53 \mathrm{hr}$, figure 6 . At $16.16 \mathrm{hr}$, the damage has grown to three adjacent teeth as shown in figure 7 . The test was terminated when a breakage is detected on one of the three heavily pitted teeth at $17.79 \mathrm{hr}$, as shown in figure 8 .

Figure 10 depicts the running speed of the test rig during various stages of the experiment. Note that there is some fluctuations present in the running speed after each shutdown, with a magnitude of approximately 6 percent about the nominal pinion speed of $14,400 \mathrm{rpm}$. There is a sharp change in speed at approximately $8.75 \mathrm{hr}$. These 
variations in speed create a substantial effect on the vibration signal, which is amplified in the NA4 (fig. 13), NB4 (fig. 14), and the WVD (fig. 21) analysis.

Figure 11 shows the results of the FM0 analysis. As seen from the figure, FM0 shows only moderate changes as the damage starts and progresses. It does not provide any indication as the damages extends to the adjacent teeth, resulting in pinion tooth fracture. The majority of the variations in the FM0 parameter are most probably due to the speed changes experienced during the test.

Results from the FM4 parameter, as seen in figure 12, shows a possible reaction as the pitting started to occur, however, it does not provide any coherent indication of the severity of the pitting as the damage increased. In addition, it does not provide any information to distinguish the pitting of a single or multiple teeth.

Results from NA4 and NA4* are illustrated in figure 13. It is obvious from the figure that both NA4 and NA4* provide a very good indication of the pitting development on the pinion tooth. The magnitude of the parameter increases to a nondimensional value of 7 after shutdown \#2 at $6.55 \mathrm{hr}$, and further to a value of 17 when the pitting covers 75 percent of the tooth surface at $8.5 \mathrm{hr}$. As expected, the "locked" denominator in NA4* provides a more robust indication as the pitting progresses. ${ }^{4,21}$ Again, both parameters are very sensitive to the speed variations, especially after shutdown \#3 and \#6.

The NB4 and NB4* parameters, as shown in figure 14, show a very similar trend to those of NA4 and NA4*, with a more robust indication to the severity of the damage. However, both NA4 and NB4 did not provide any type of indication as the damage spread to other teeth, and finally as tooth fracture occurred.

Figure 15 shows a WVD (and corresponding intensity scale) and below the WVD the frequency spectrum (from FFT analysis) of a uniform sine wave signal shown at the left side of the figure. Note that only the frequency component of the input frequency is detected by both the frequency domain analysis and the joint time-frequency distribution. The WVD does not exhibit any changes during the 1 cycle ( 0 to 360 degrees) rotation of the shaft. When a short term amplitude and phase change is added to the system, as shown in figure 16, the frequency spectrum remains virtually unchanged. The WVD shows a dramatic change of the energy distribution pattern at the location where the change occurs. The lighter shades of the distribution display indicates a smaller vibration amplitude, which is shown by the time signal at the left side of the figure. Such an effect could be possibly caused by a chipped or cracked tooth. Figure 17 shows the effects of a short term amplitude increase in the time signal to simulate vibrations caused by gear tooth surface damage. Note that the frequen- cy spectrum remains the same showing only the component of the exciting frequency while the WVD again provides a good indication of the amplitude increase by the widening of the shaded area to a diamond shape at the corresponding "damaged" tooth location. Figure 18 shows the effects of a time decaying short term amplitude and phase change signal. The WVD shows a half diamond shape of shaded area, similar to that of figure 16 , at the location where the amplitude and phase changes are presented. As seen in figure 18 , the frequency spectrum gives very little indication of the signal change.

Figures 19 to 26 show the WVD and frequency spectra of the spiral bevel pinion vibration at various stages of damage, corresponding to the photographs given in figures 1 to 8 . Figure 19 shows the occurrence of the initial pitting at around 200 degrees from the triggering point of the gear, at $5.5 \mathrm{hr}$, of running time. At $6.55 \mathrm{hr}$, the pitting on the tooth surface progressed to a more noticable stage, as shown in figure 2, the WVD pattern, figure 20 , begins to adopt those of a short term amplitude and phase change as illustrated in figure 18. Due to the speed increase at $8.55 \mathrm{hr}$, the overall WVD amplitude increases substantially as shown in figure 21. At the running time of $10.03 \mathrm{hr}$, the corresponding WVD in figure 22 shows the initiation of a cross pattern as surface pitting in the damaged tooth becomes more pronounced which can also be evidented from the photograph of the pinion gear in figure 4. This phenomenon is also evident in the frequency spectrum with the existence of sideband components. At $12.03 \mathrm{hr}$, when the pitting on the pinion tooth hax extended to about 75 percent of the tooth surface as shown in figure 5, the WVD pattern exhibits a solid cross pattern extending over the mesh freqeuncy and several of its adjacent sidebands. The high concentration in the WVD energy and the initiation of a second cross pattern at $14.53 \mathrm{hr}$, figure 24 , shows the advancement of the pitting process on second tooth, as illustrated in figure 6. This is further confirmed by the large amplitude of sideband component(above mesh) in the frequency spectrum. At $16.16 \mathrm{hr}$, as seen in figure 25 , the WVD pattern changes, showing more advanced damage pattern similar to the multiples of the decay of a single short term amplitude increase and phase change demonstrated in figure 18. Such phenomenon is due to the pitting of three consecutive teeth in the pinion gear as shown in the picture given in figure 7. The frequency spectrum in figure 25 shows a substantial amplitudes increase in the sideband components. The discontinuity of the WVD at the mesh frequency, shown in figure 26 , similar to the example shown in figure 16 due to the short term phase change, is probably the result of the instantaneous phase change caused by the fractured tooth, as illustrated in figure 8 . The two cross patterns in the WVD is very distinct as the effects of pitting at the teeth adjacent to the fracture tooth become more pronounced. Note, also that, as given in figure 26 , the amplitude of the sideband frequencies(above and below the mesh frequency) increase substantially. 


\section{$\underline{\text { V. Conclsuions }}$}

Based on the results of the application of the various aforementioned methods, the following conclusions can be made:

1) The FM0 parameter shows only moderate changes as the damage starts and progresses. It also fails to indicate the fracture of the pinion tooth.

2) The FM4 parameter shows a possible reaction to the start of the pitting process, however, no coherent indication is provided for the growth and severity of the pit.

3) The NA4* and NB4* parameters show good reactions to the initial pitting damage and very nice indications for the growth and severity of the pitting damage. However their indications for the tooth fracture is somewhat unclear.

4) The WVD provides vital information concerning both the severity and the location of the pitting process in the gear system.

5) The fracture of the gear tooth and its exact location can be pinpointed using the WVD technique. However a machine vibration signature database is required to interpret the resulting WVD.

6) The occurrence and the severity of gear tooth failure can be reliably detected using a combination of the time averaging, the frequency analysis, and the WVD techniques.

\section{References}

1. Boashash, B. and Black, P.J. "An efficient Real-Time Implementation of the Wigner-Ville Distribution" IEEE Trans. on Acoustics, Speech, and Signal Processing, Vol. ASSP-35, No. 11, November 1987.

2. Bouachache, B. and Flandrin, P., "Wigner-Ville Analysis of Time-Varying signals," CH $1746782 / 00-$ 00, 1329 IEEE 1982.

3. Claasen, T.A.C.M., and Mecklenbräuker, W.F.G., "The Wigner Distribution - A tool for Time-Frequency Signal Analysis," Part I Philip J. Res. 35, 1980.

4. Decker, H.J., Handschuh, R.F., and Zakrajsek, J.J., "An Enhancement to the NAU Gear Vibration Diagnostic Parameter," NASA TM-106553, presented at the 18th Annual Meeting of the Vibration Institute, Hershey, PA, June 20-23, 1994.

5. Forrester, B.D., "Analysis of Gear Vibration in the Time-Frequency Domain," Proc. of the 44th Meeting of the Mechanical Failure Prevenention Group. Feb. 1990.
6. Frandrin, P., "NonDestructive Evaluation in the TimeFrequency Domain by Means of the Wigner-Ville Distribution," NATO ASI Series, Vol. I44, pp. 109-116.

7. Handschuh, R., "Effect of Lubricant Jet Location on Spiral Bevel Gear Operating Temperatures," NASA TM-105656, AUSCOM TR-91-C-033, presented at the 6th International Power Transmission and Gearing Conference, ASME Sept. 13-16, 1992, Phoenix, AZ.

8. Howard, I.M., and Forrester, B.D., "A UH-60A Main Transmission Operating With a Natural Fault in a Test Stand During a Qualification Test," Preliminary Vibration Diagnostic Report, 1992.

9. Macfadden, P.D., and Smith, J.D., "A Signal Processing Technique for Detecting Local Defects in a Gear From the Signal Average of the Vibration," Proc. Inst. Mech. Engrs., Vol. 199, No. c4, 1985.

10. Mcfadden, P.D., "Detecting Fatique Cracks in Gears by Amplitude and Phase Demodulation of the Meshing Vibration," Journal of Vibration, Acoustics, Stress, and Reliability in Design. Apr. 1986, Vol. 108.

11. Mcfadden, P.D., "Examination of a Technique for the Early Detection of Failure in Gears by Signal Processing of the Time Domain Average of the Meshing Vibration," Mechanical System and Signal Processing, (1987), 1(2), pp. 173-183.

12. Mcfadden, P.D. and Wang, W.J. "Time-Frequency Domain Analysis of Vibration Signal for Machinery Diagnostics (II) the Weighted Wigner-Ville Distribution", University of Oxford, Report No. OUEL 1891 , 1991.

13. Narayanan, S.B., and Prabnu, K.M.M., "New Method of Computing Wigner-Ville Distribution," Electronics Letters, 2nd March 1989, Vol. 25, No. 5.

14. Peyrin, F., and Prost, R., "A Uniform Definiton for the Discrete-Time, Discrete-Frequency, and DiscreteTime/Frequency Wigner Distribution," IEEE Transaction on Acoustics, Speech and Signal Processing, Vol. ASS-34 No. 4, Aug. 1986.

15. Randall, R.B., "A new Method of Modeling Gear Faults," Journal of Mechanical Design, Apr. 1982, Vol. 104/259.

16. Shin, Y.S. and Jeon, J.J. "Pseudo Wigner-Ville TimeFrequency Distribution and its Application to Machinery Condition Monitoring", J. of Shock and Vibration, Vol. 1, Issue 1, 1993/1994, pp. 65. 
17. Stewart, R.M., "Some Useful Data Analysis Techniques for Gearbox Diagnostics," Institute of Sound and Vibration Research, Paper MHM/R/10/77, 1977.

18. Taylor, J.I., "Fault Diagnosis of Gears Using Spectrum Analysis," Second International Conference on Vibrations in Rotating Machines, Cambridge, Sept. 2-4, 1980, I. Mech. E., London, pp. 163-168.

19. Zakrajsek, J.J., "An Investigation of Gear Mesh Failure Prediction Technique," NASA AVSCOM, TECHNICAL MEMORANDUM 102340, 1989.
20. Zakrajsek, J.J., Towsend, D.P. and Decker, H.J. "An Analysis of Gear Fault Detection Methods as Applied to Pitting Fatigue Failure Data", NASA TM-105950, presented at the 47th Mechanical Failure Prevention Group Meeting, Virginia Beach, Virginia, April 13-15, 1993.

21. Zakrajsek, J.J., Handschuh, R.F., and Decker, H.J. "Application of Fault Detection Techniques to Spiral Bevel Gear Fatique Data", NASA TM-106467, presented in the 48th Mechanical Failures Prevention Group Meeting, Wakefield, Massachusetts, April 19-21, 1994. 


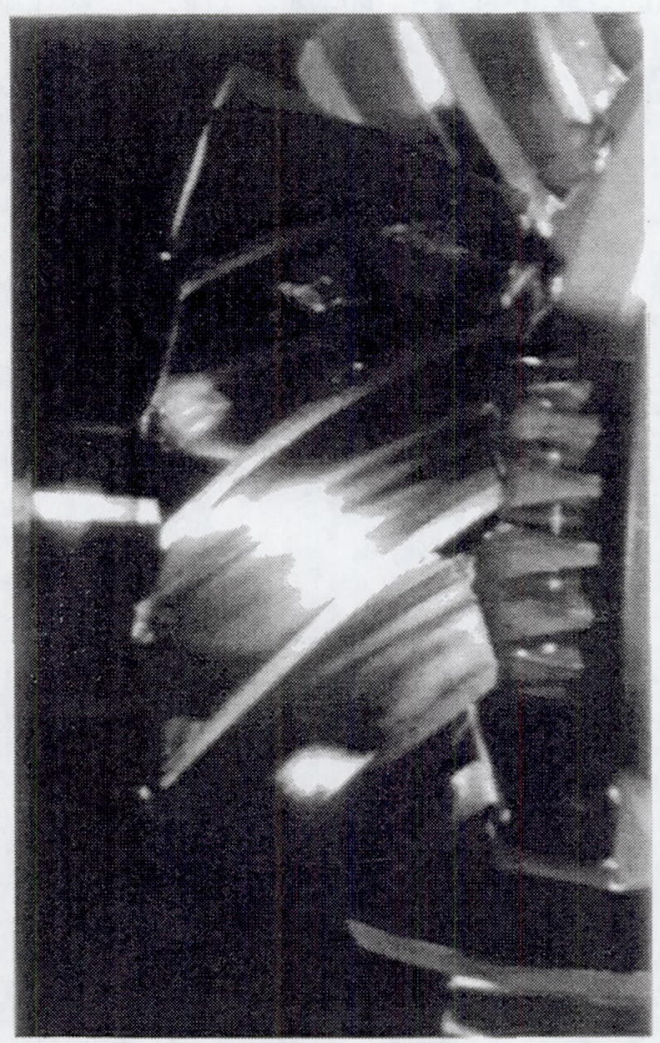

Figure 1.-Photograph of pinion damage at $t=5.50 \mathrm{hr}$.

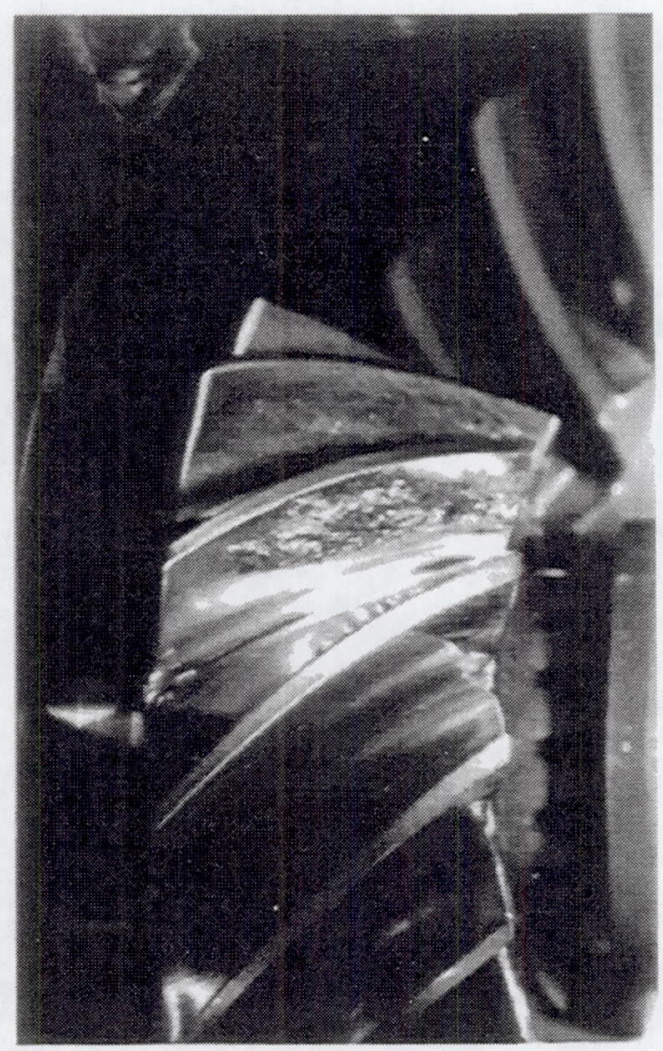

Figure 3.-Photograph of pinion damage at $t=8.55 \mathrm{hr}$.

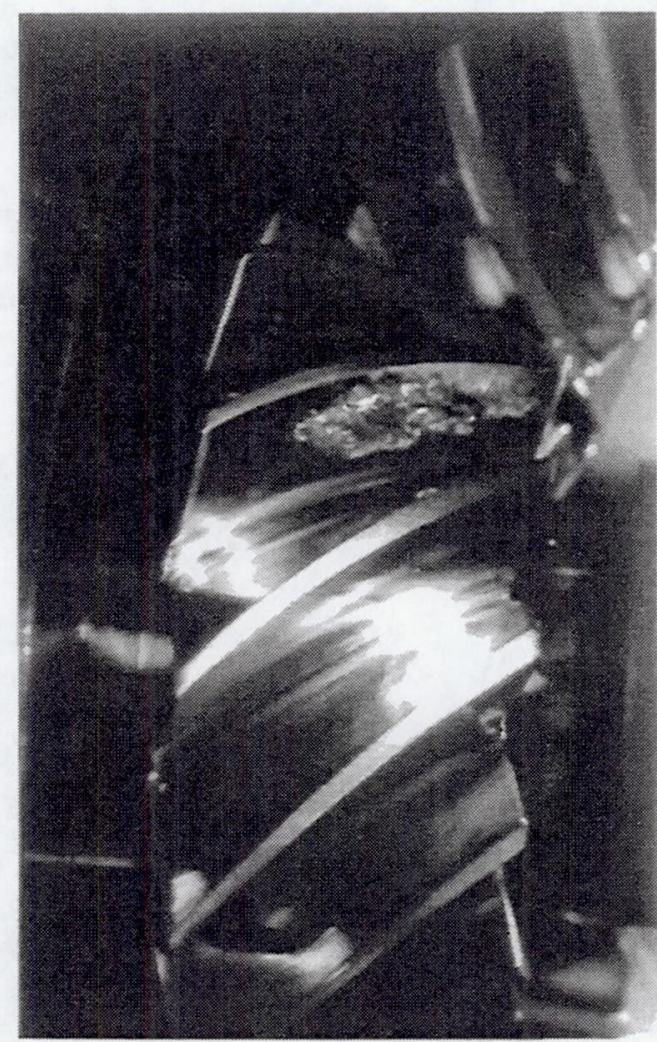

Figure 2.-Photograph of pinion damage at $\mathrm{t}=6.55 \mathrm{hr}$.

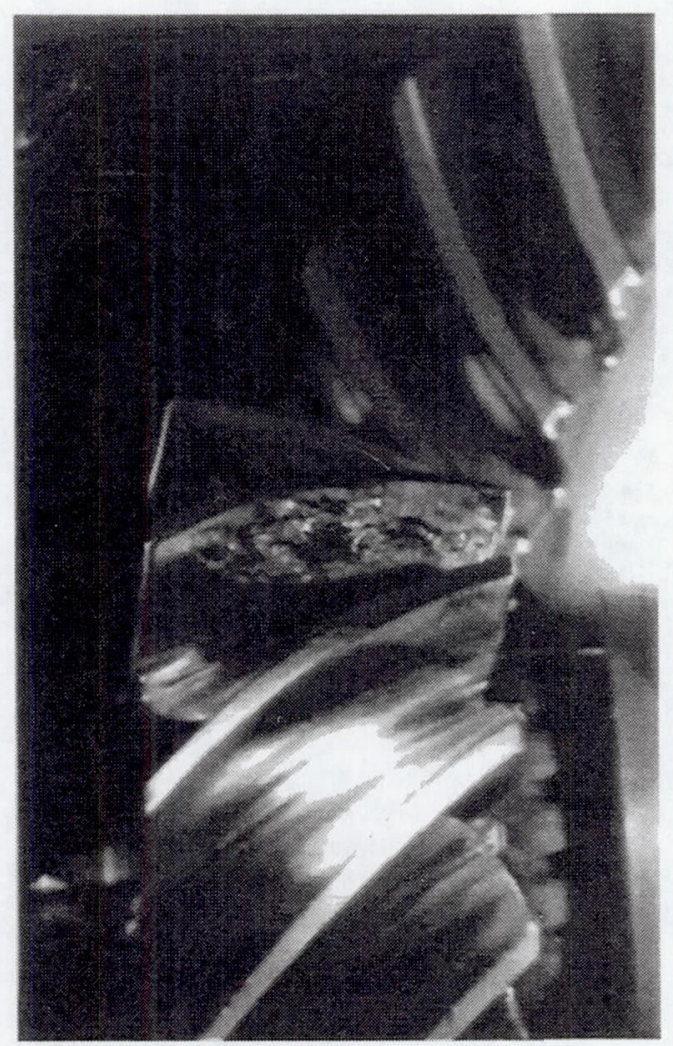

Figure 4.-Photograph of pinion damage at $\mathrm{t}=10.03 \mathrm{hr}$. 


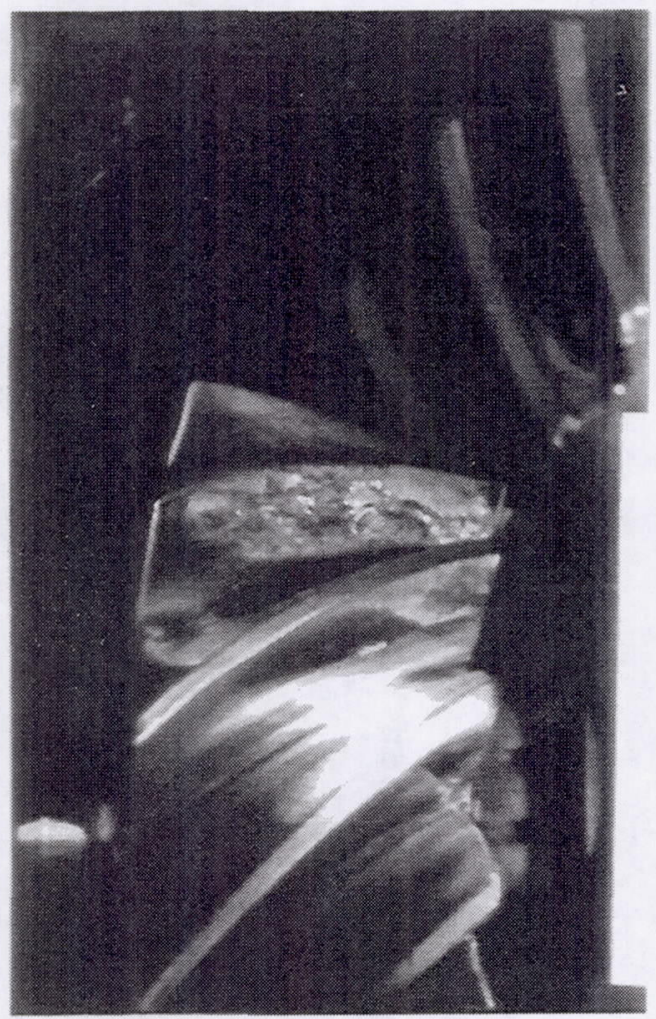

Figure 5.-Photograph of pinion damage at $t=12.03 \mathrm{hr}$.

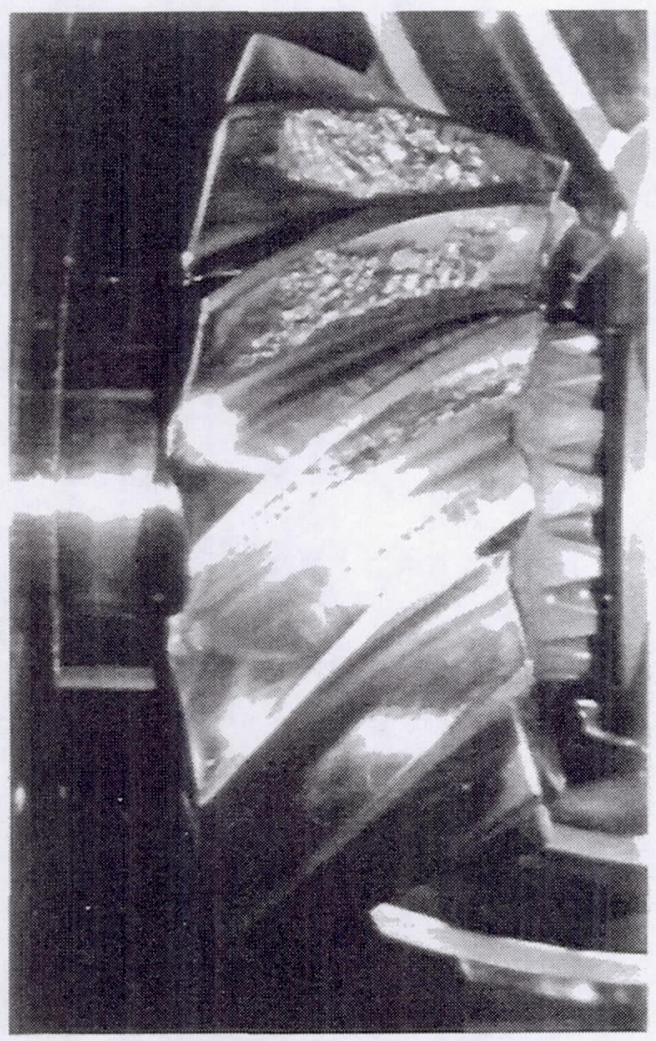

Figure 7.-Photograph of pinion damage at $\mathrm{t}=16.16 \mathrm{hr}$.

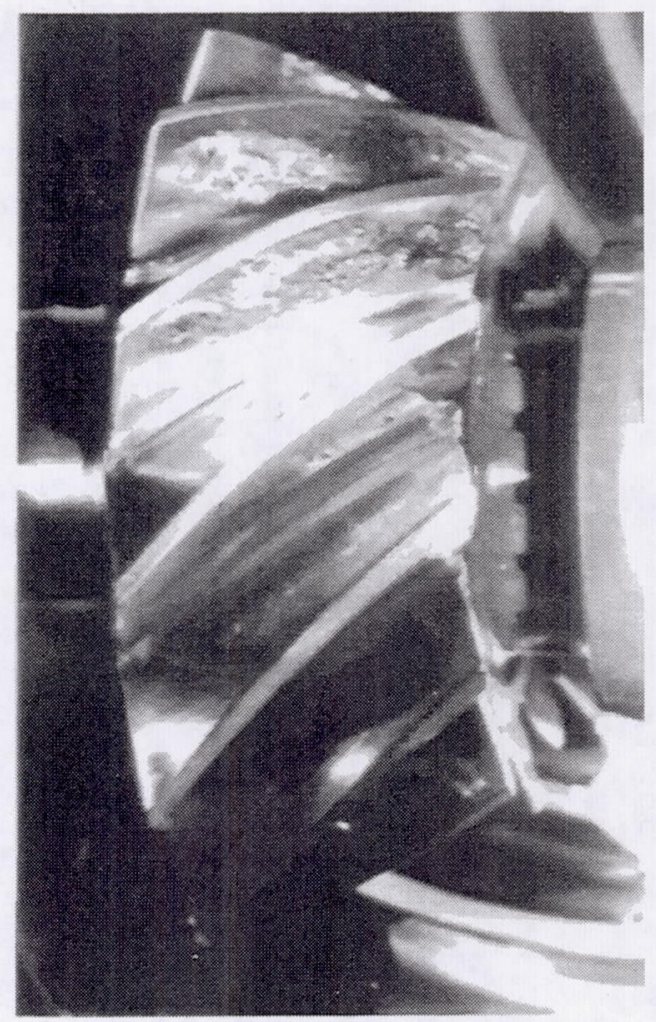

Figure 6.-Photograph of pinion damage at $t=14.53 \mathrm{hr}$.

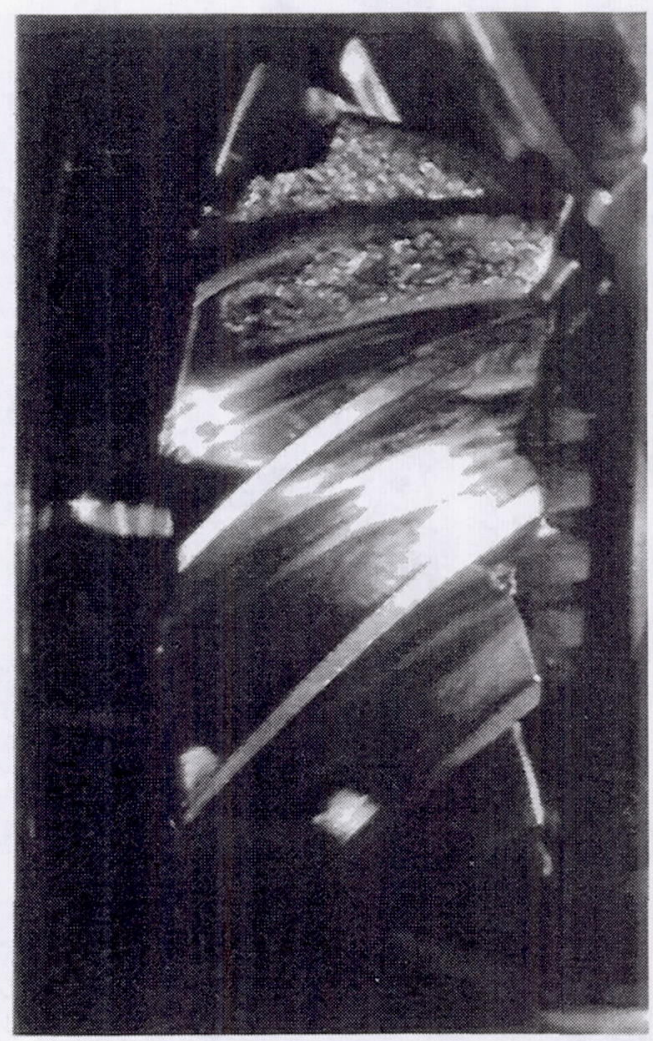

Figure 8.-Photograph of pinion damage at $\mathrm{t}=17.79 \mathrm{hr}$ (end of run). 


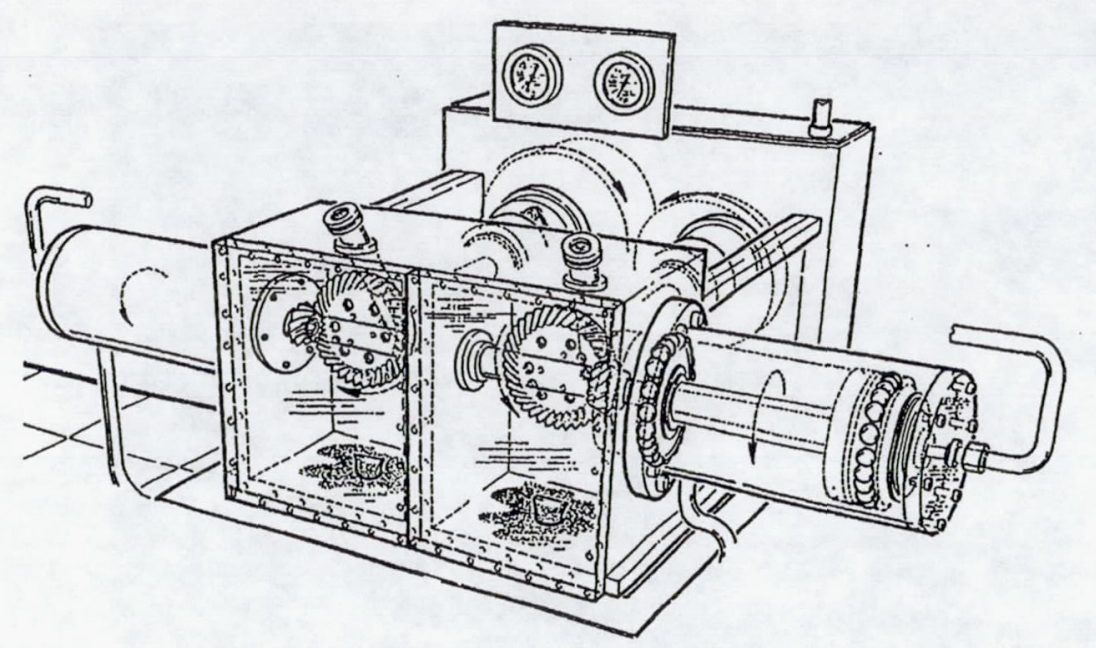

Figure 9.-Spiral bevel gear fatigue test rig at NASA Lewis Research Center.

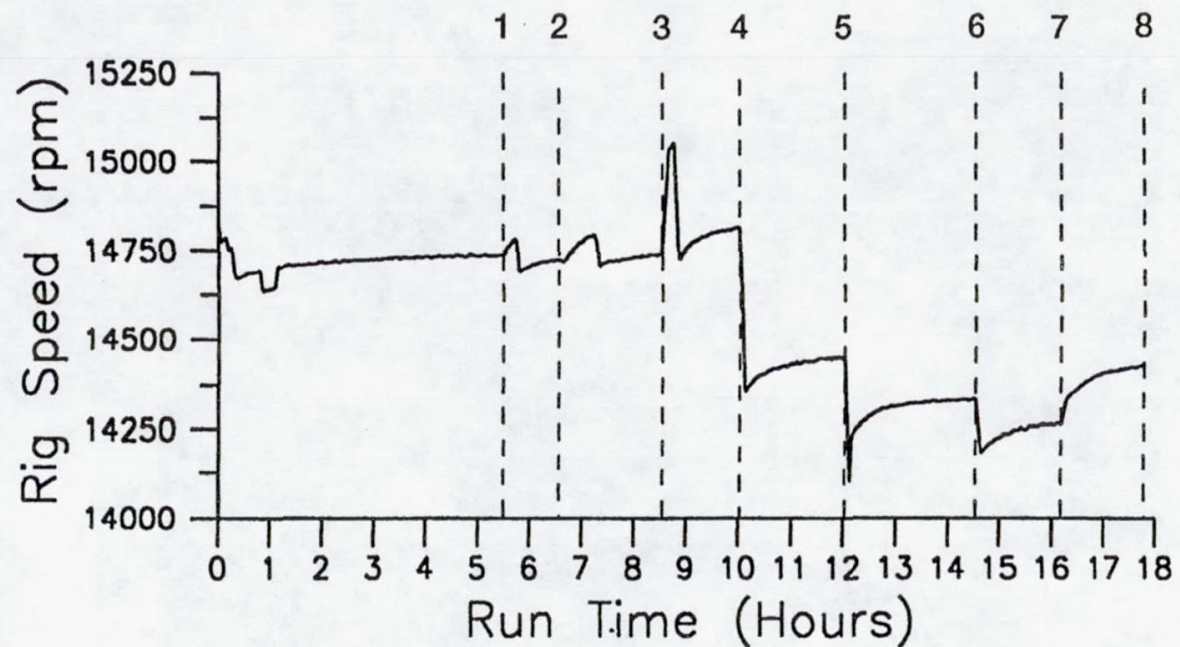

Figure 10.-Rig operating speed at various run time.

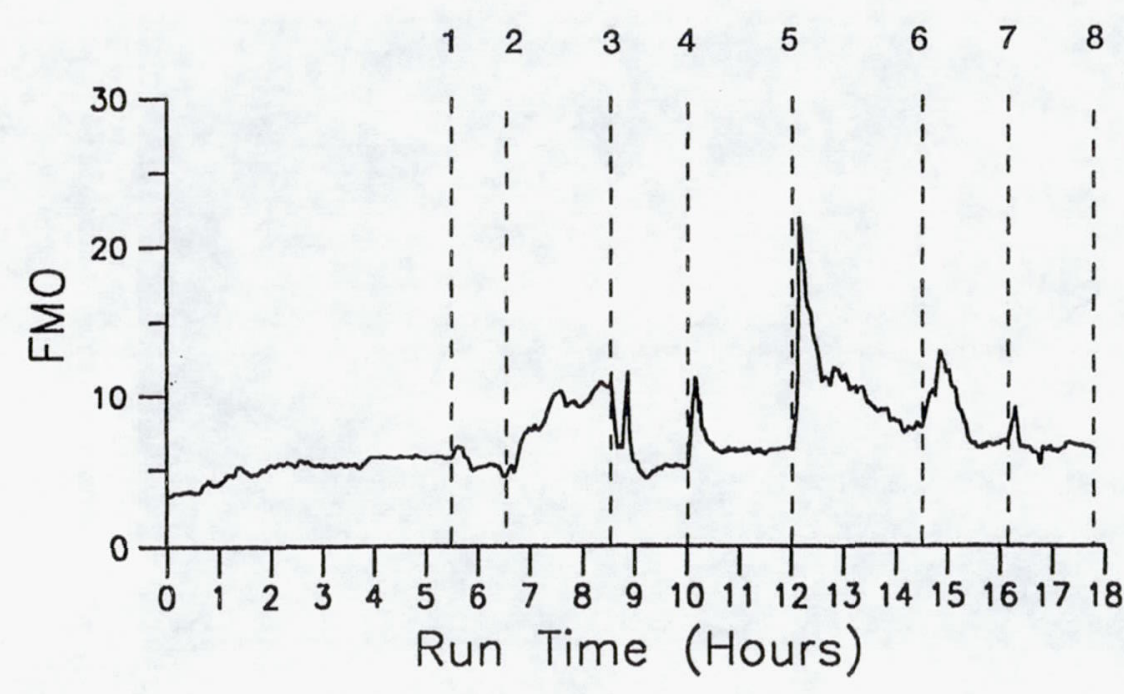

Figure 11.-FM0 parameter at various run time.

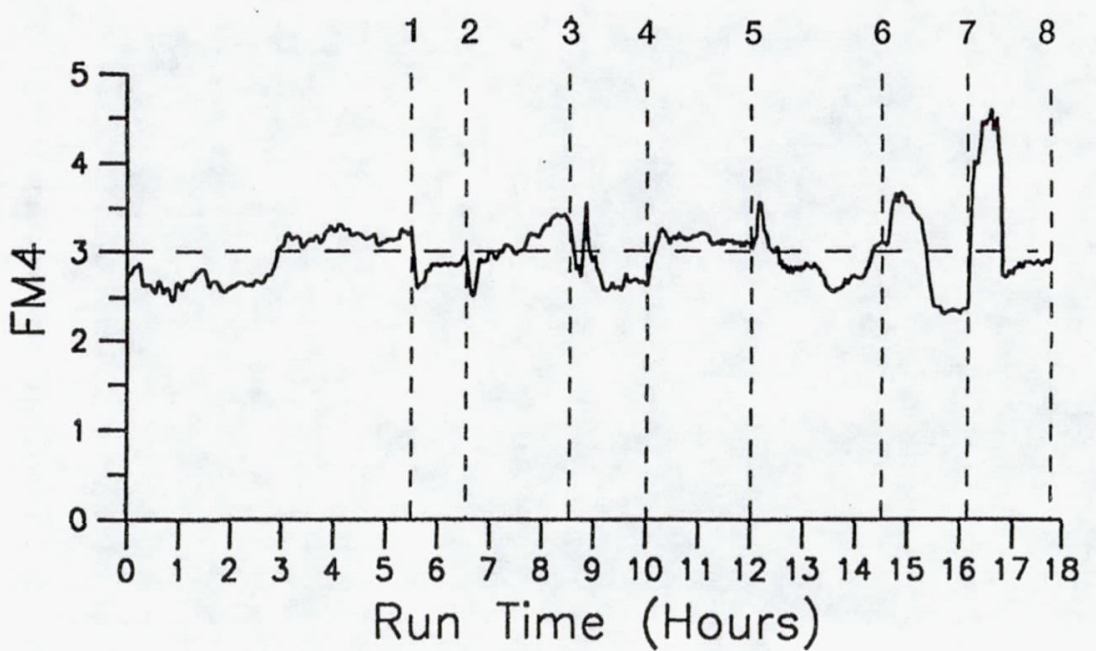

Figure 12.-FM4 parameter at various run time. 


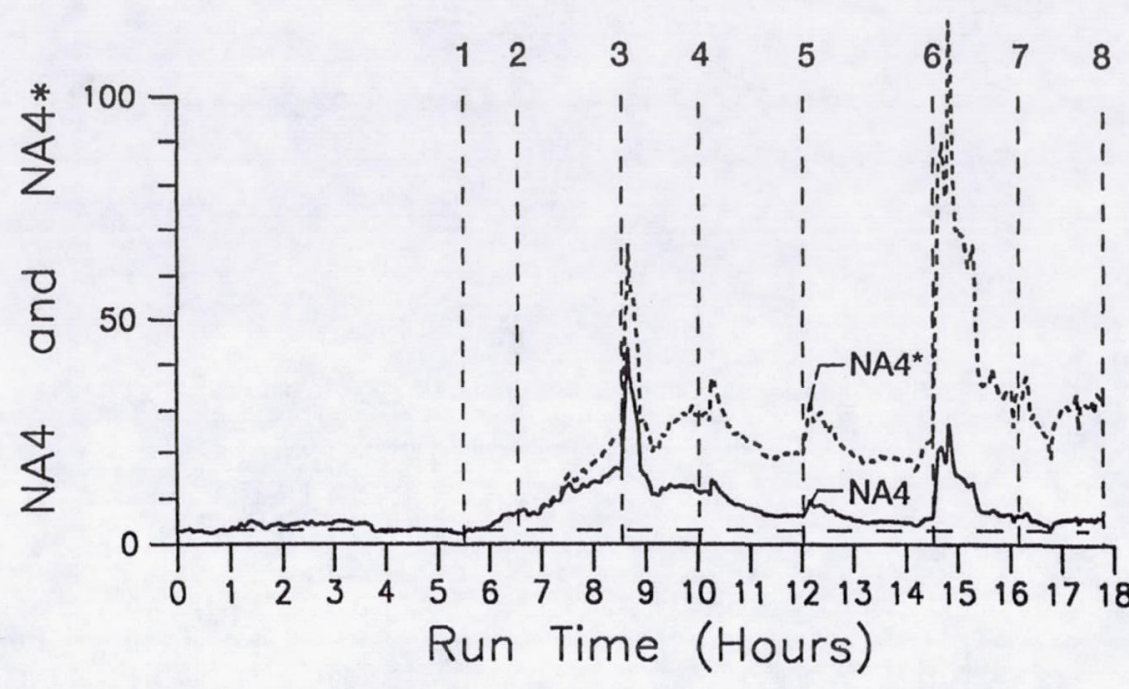

Figure 13.-NA4 and NA4* at various run time.
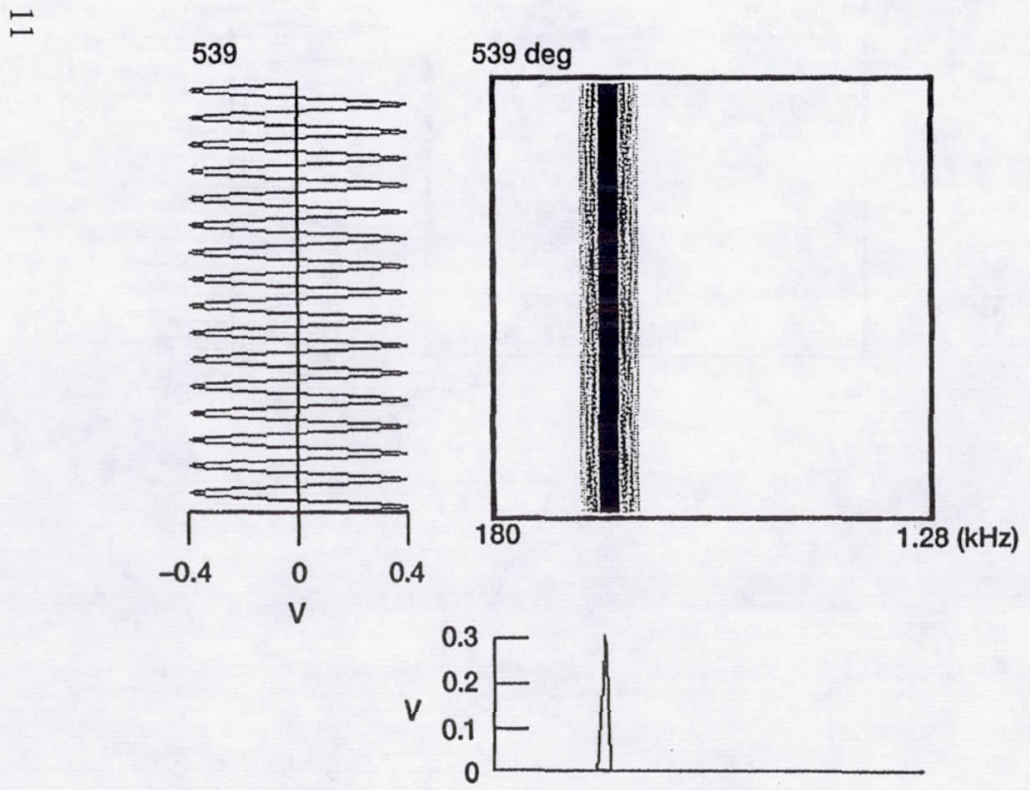

Figure 15.-Example of WVD on a regular sine wave time signal.

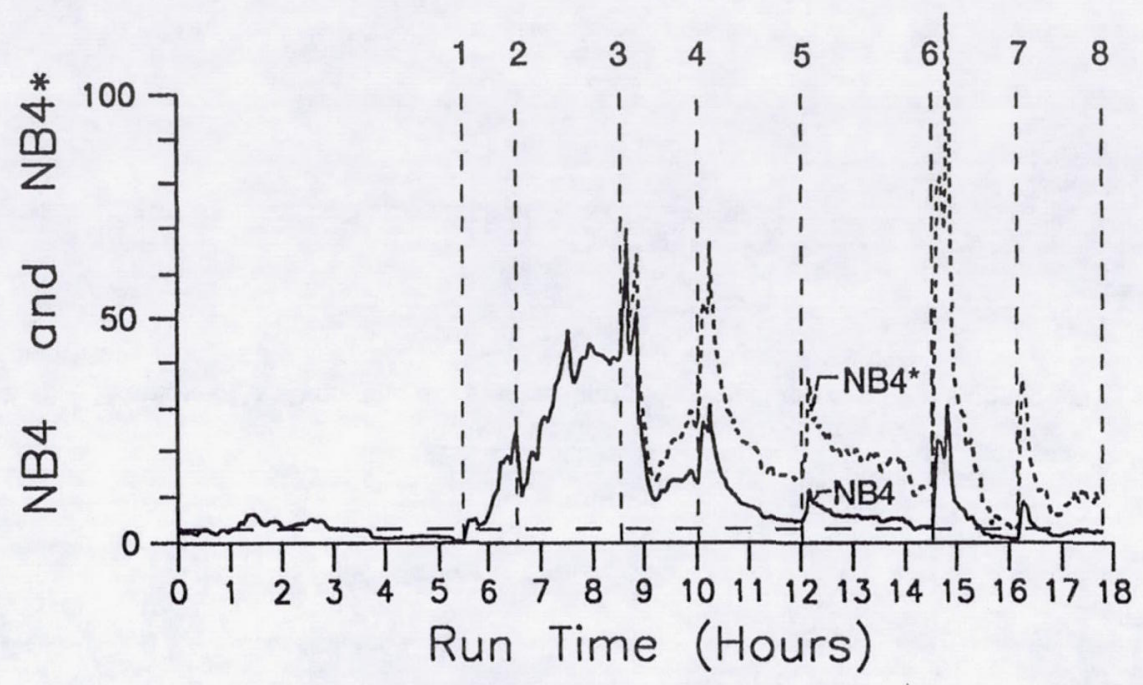

Figure 14.-NB4 and NB4* at various run time.
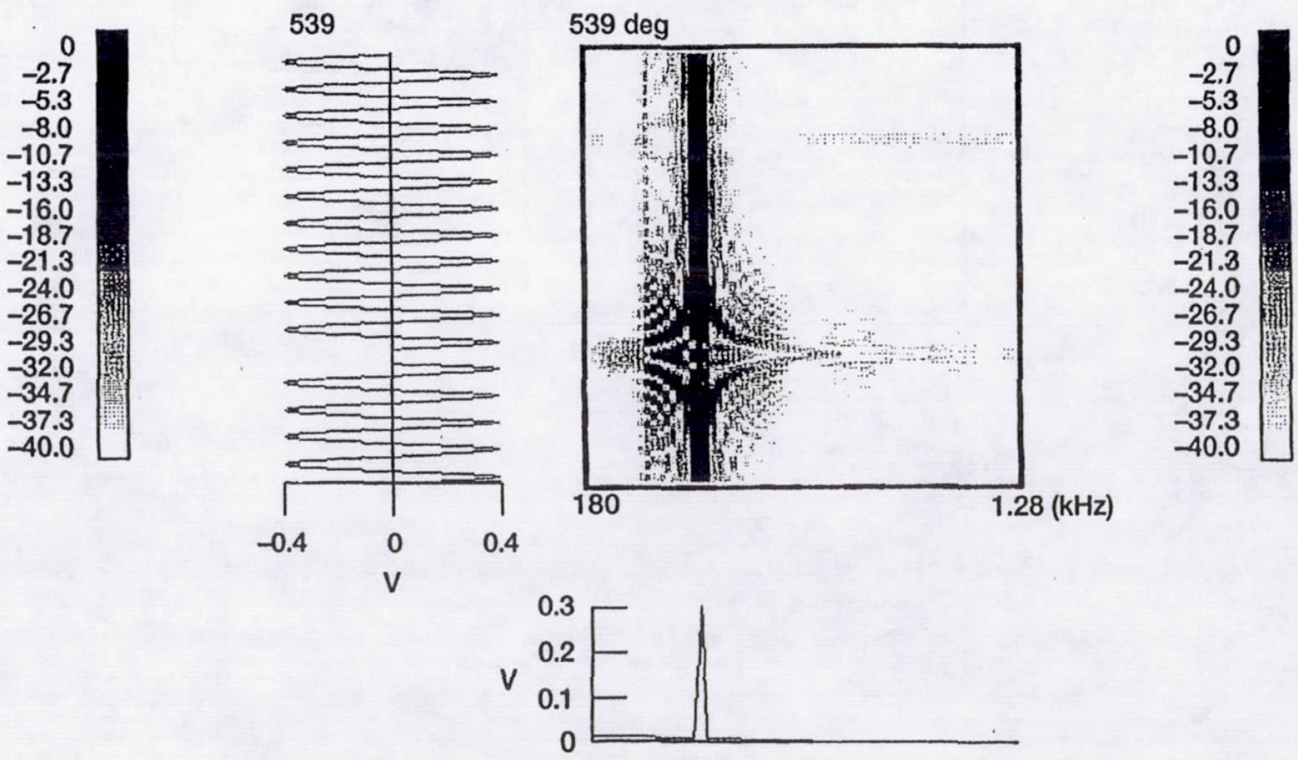

Figure 16.-Example of WVD on short term amplitude and phase change in a signal. 


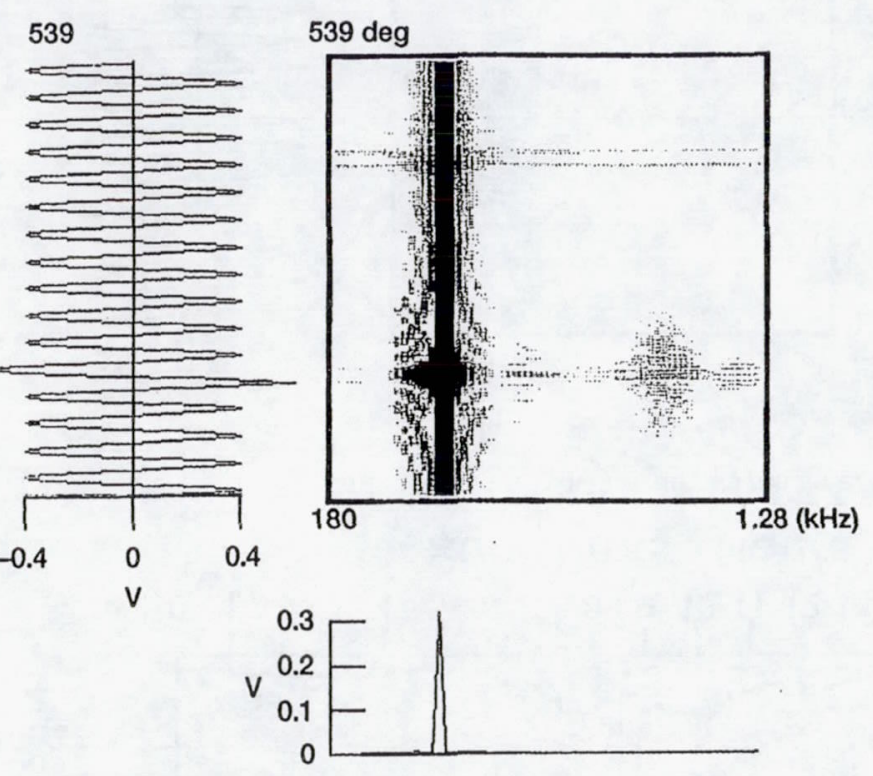

Figure 17.-Example of WVD on short term amplitude increase in a signal.

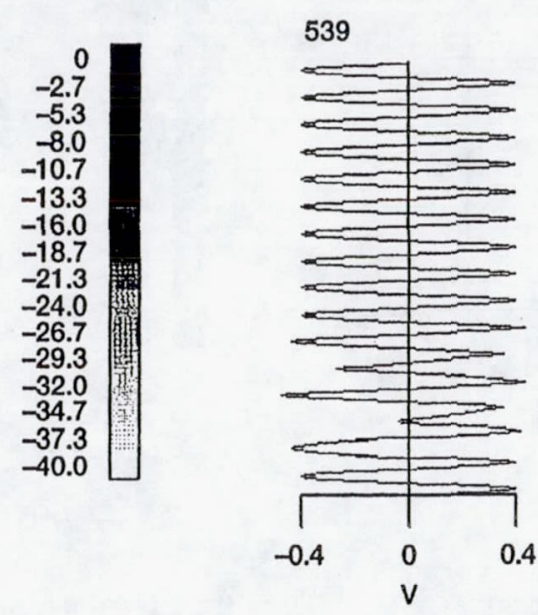

$539 \mathrm{deg}$

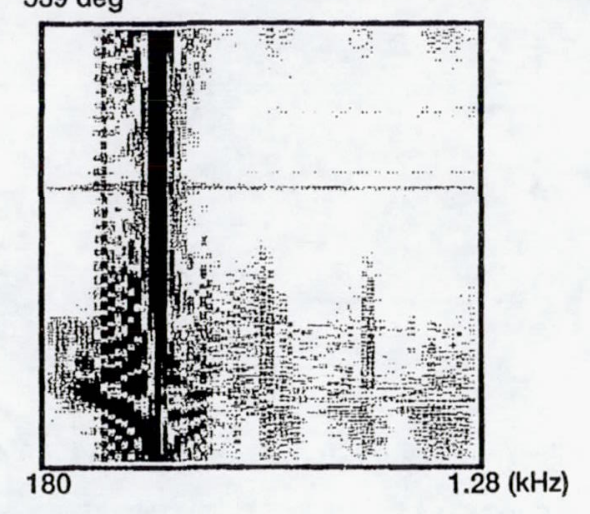

0
-2.7
-5.3
-8.0
-10.7
-13.3
-16.0
-18.7
-21.3
-24.0
-26.7
-29.3
-32.0
-34.7
-37.3
-40.0

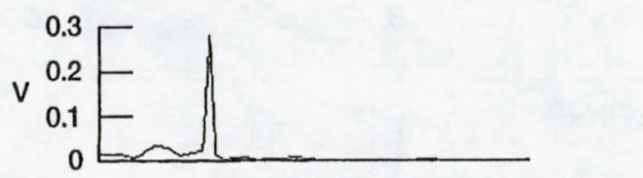

Figure 18.-Example of WVD on time decay of a short term amplitude and phase change in a signal. 


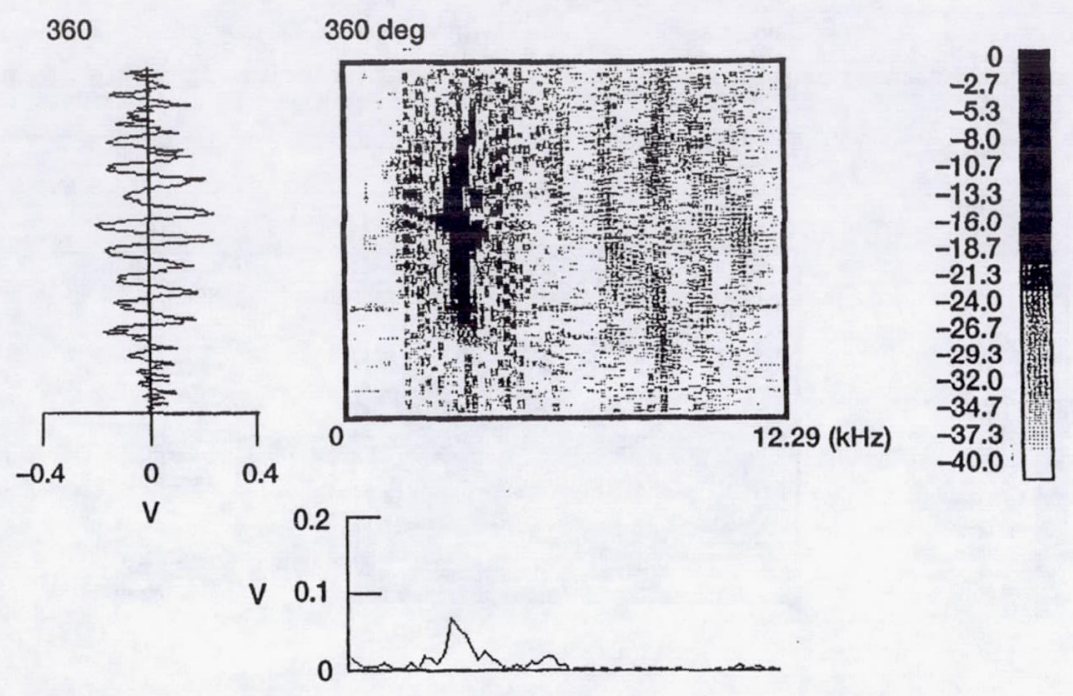

Figure 19.-Application of WVD to the spiral bevel gear vibration signal at $5.50 \mathrm{hr}$.

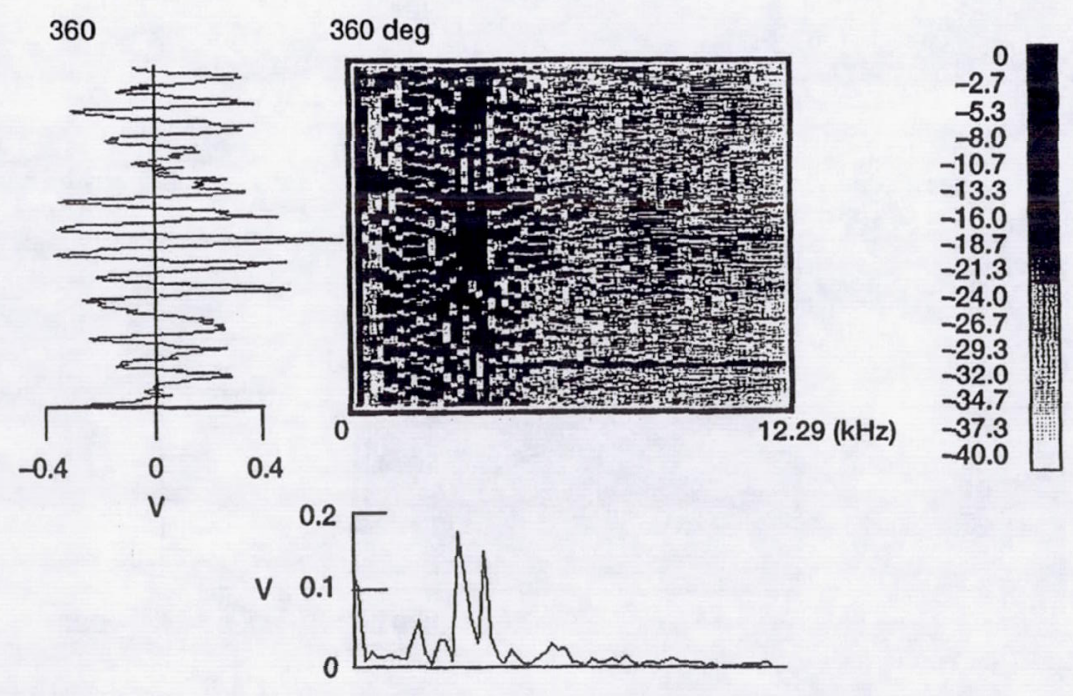

Figure 21.-Application of WVD to the spiral bevel gear vibration signal at $8.55 \mathrm{hr}$.

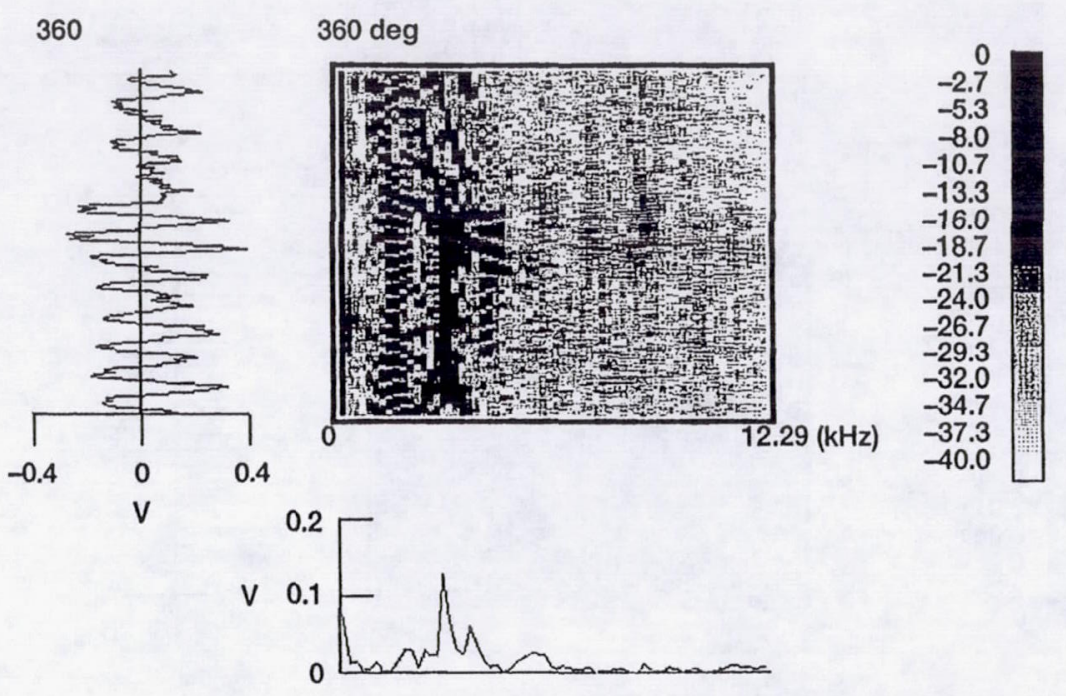

Figure 20.-Application of WVD to the spiral bevel gear vibration signal at $6.55 \mathrm{hr}$.
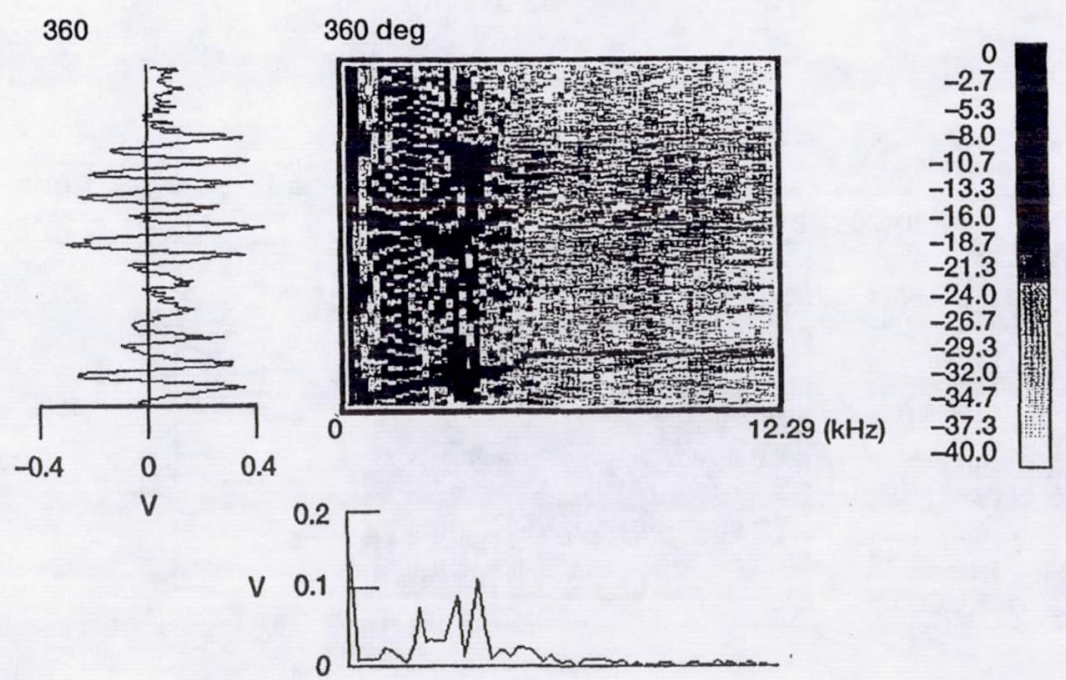

Figure 22.-Application of WVD to the spiral bevel gear vibration signal at $10.03 \mathrm{hr}$. 


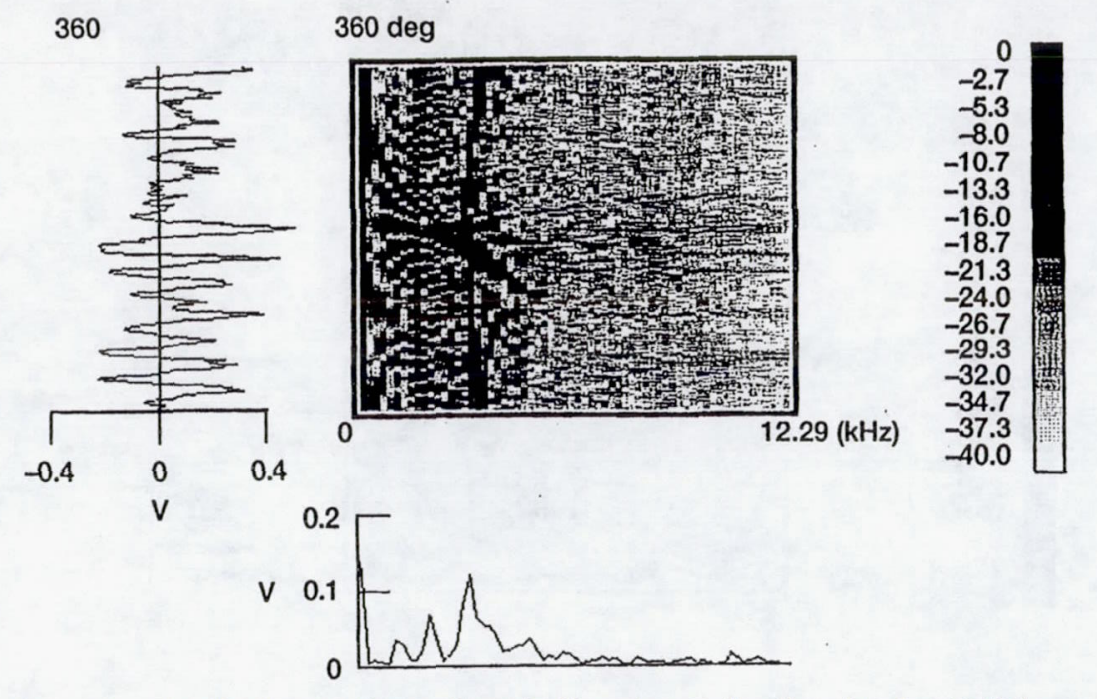

Figure 23.-Application of WVD to the spiral bevel gear vibration signal at $12.03 \mathrm{hr}$.

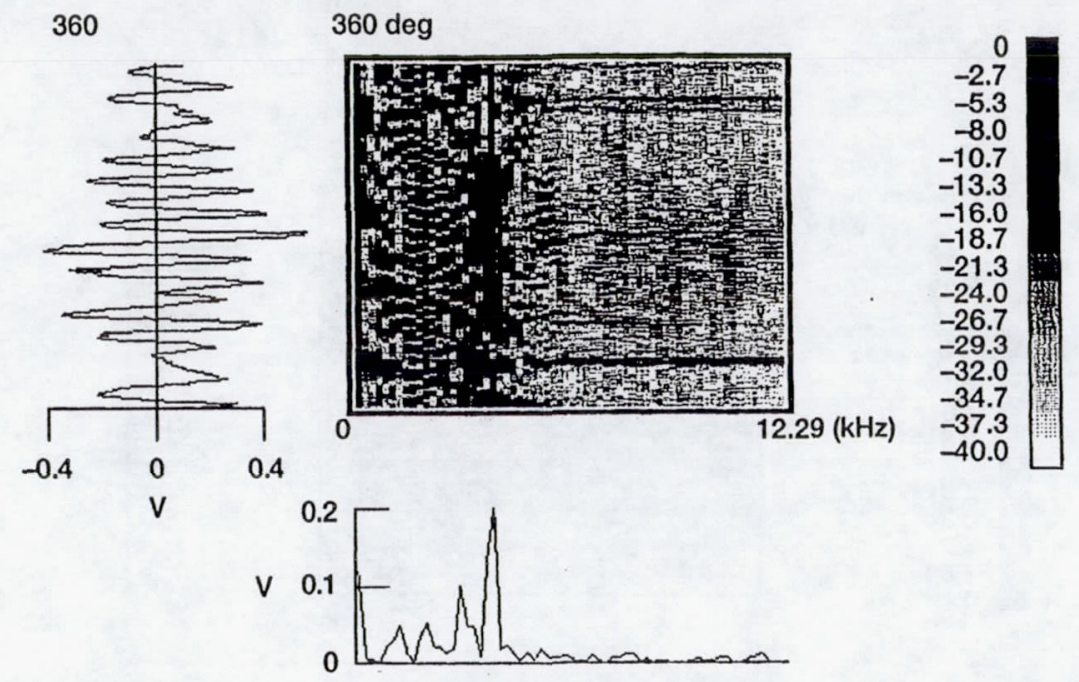

Figure 24.-Application of WVD to the spiral bevel gear vibration signal at $14.53 \mathrm{hr}$.

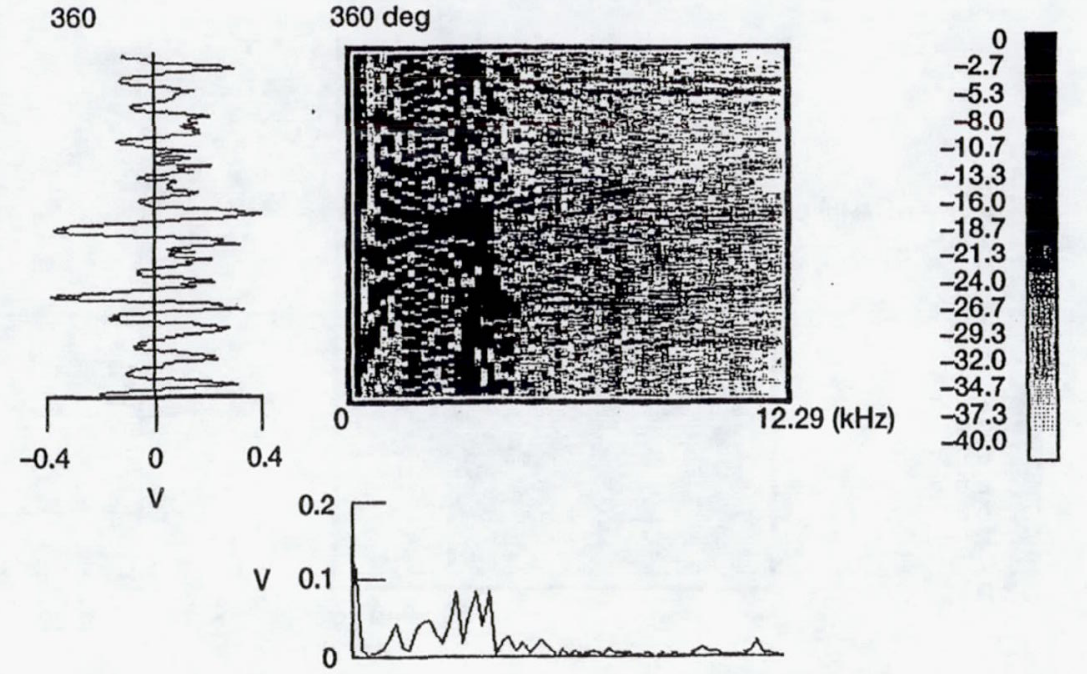

Figure 25.-Application of WVD to the spiral bevel gear vibration signal at $16.16 \mathrm{hr}$.
360

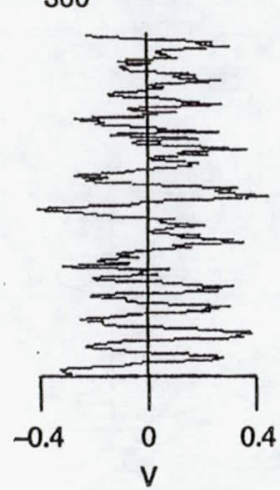

$360 \mathrm{deg}$

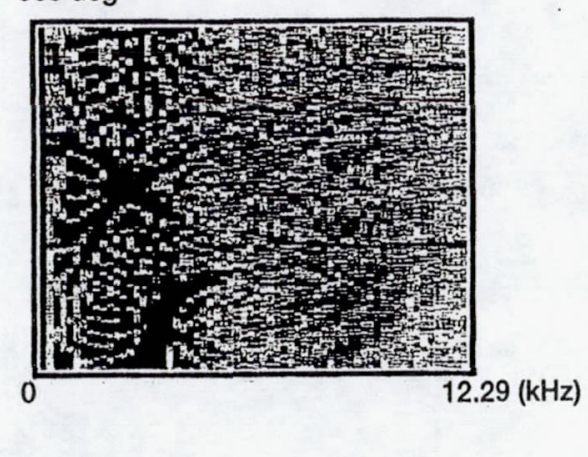

0
-2.7
-5.3
-8.0
-10.7
-13.3
-16.0
-18.7
-21.3
-24.0
-26.7
-29.3
-32.0
-34.7
-37.3
-40.0

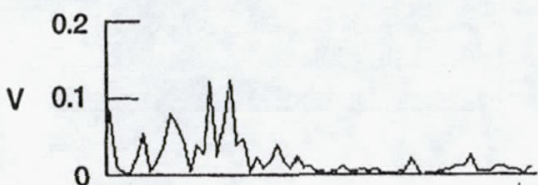

Figure 26.-Application of WVD to the spiral bevel gear vibration signal at $17.79 \mathrm{hr}$. (end of run). 
Public reporting burden for this collection of information is estimated to average 1 hour per response, including the time for reviewing instructions, searching existing data sources, gathering and maintaining the data needed, and completing and reviewing the collection of information. Send comments regarding this burden estimate or any other aspect of this Davis Highway, Suite 1204, Arlington, VA 22202-4302, and to the Office of Management and Budget, Paperwork Reduction Project (0704-0188), Washington, DC 20503.

\begin{tabular}{|l|l|l}
\hline 1. AGENCY USE ONLY (Leave blank) & $\begin{array}{c}\text { 2. REPORT DATE } \\
\text { June } 1994\end{array}$ & $\begin{array}{r}\text { 3. REPORT TYPE AND DATES COVERED } \\
\text { Technical Memorandum }\end{array}$
\end{tabular}

\section{TITLE AND SUBTITLE}

5. FUNDING NUMBERS

Vibration Signature Analysis of a Faulted Gear Transmission System

6UTHOR(S)

WU-505-62-36

F.K. Choy, S. Huang, J.J. Zakrajsek, R.F. Handschuh, and D.P. Townsend

1L162211A47A

7. PERFORMING ORGANIZATION NAME(S) AND ADDRESS(ES)

NASA Lewis Research Center

8. PERFORMING ORGANIZATION

Cleveland, Ohio 44135-3191

and

Vehicle Propulsion Directorate

U.S. Army Research Laboratory

Cleveland, Ohio 44135-3191

9. SPONSORING/MONITORING AGENCY NAME(S) AND ADDRESS(ES)

National Aeronautics and Space Administration

Washington, D.C. 20546-0001

and

U.S. Army Research Laboratory

Adelphi, Maryland 20783-1145

\section{REPORT NUMBER}

E-8914

10. SPONSORING/MONITORING AGENCY REPORT NUMBER

NASA TM-106623

ARL-TR-475

AIAA-94-2937

11. SUPPLEMENTARY NOTES

Prepared for the 30th Joint Propulsion Conference cosponsored by the AIAA, ASME, SAE, and ASEE, Indianapolis, Indiana, June 27-29, 1994.

F.K. Choy and S. Huang, University of Akron, Department of Mechanical Engineering, Akron, Ohio 44325; J.J. Zakrajsek, NASA Lewis Research

Center; R.F. Handschuh, Vehicle Propulsion Directorate, U.S. Army Research Laboratory, Lewis Research Center, Cleveland, Ohio 44135; and

D.P. Townsend, NASA Lewis Research Center. Responsible person, J.J. Zakrajsek, organization code 2730, (216) 433-3968.

12a. DISTRIBUTION/AVAILABILITY STATEMENT

12b. DISTRIBUTION CODE

Unclassified - Unlimited

Subject Category 37

13. ABSTRACT (Maximum 200 words)

A comprehensive procedure in predicting faults in gear transmission systems under normal operating conditions is presented. Experimental data was obtained from a spiral bevel gear fatigue test rig at NASA Lewis Research Center. Time synchronous averaged vibration data was recorded throughout the test as the fault progressed from a small single pit to severe pitting over several teeth, and finally tooth fracture. A numerical procedure based on the Winger-Ville distribution was used to examine the time averaged vibration data. Results from the Wigner-Ville procedure are compared to results from a variety of signal analysis techniques which include time domain analysis methods and frequency analysis methods. Using photographs of the gear tooth at various stages of damage, the limitations and accuracy of the various techniques are compared and discussed. Conclusions are drawn from the comparison of the different approaches as well as the applicability of the Wigner-Ville method in predicting gear faults.

14. SUBJECT TERMS

Gear; Fatigue; Diagnostics; Failure prediction

15. NUMBER OF PAGES

16

16. PRICE CODE

$\mathrm{A} 03$

\begin{tabular}{|c|c|}
\hline $\begin{array}{c}\text { 17. SECURITY CLASSIFICATION } \\
\text { OF REPORT }\end{array}$ & $\begin{array}{c}\text { 18. SECURITY CLASSIFICATION } \\
\text { OF THIS PAGE } \\
\text { Unclassified }\end{array}$ \\
Unclassified
\end{tabular}

19. SECURITY CLASSIFICATION OF ABSTRACT

Unclassified 